\title{
KRAS mutations in cell-free DNA from preoperative and postoperative sera as a pancreatic cancer marker: a retrospective study
}

Yutaka Nakano ${ }^{1}$, Minoru Kitago*,1, Sachiko Matsuda ${ }^{1}$, Yuki Nakamura ${ }^{1}$, Yusuke Fujita ${ }^{1}$, Shunichi Imai ${ }^{1}$, Masahiro Shinoda ${ }^{1}$, Hiroshi Yagi ${ }^{1}$, Yuta Abe ${ }^{1}$, Taizo Hibi ${ }^{1}$, Yoko Fujii-Nishimura ${ }^{2}$, Ayano Takeuchi ${ }^{3}$, Yutaka Endo ${ }^{1}$, Osamu Itano ${ }^{4}$ and Yuko Kitagawa ${ }^{1}$

${ }^{1}$ Department of Surgery, Keio University School of Medicine, 35 Shinanomachi, Shinjuku-ku, Tokyo 160-8582, Japan; ${ }^{2}$ Department of Pathology, Keio University School of Medicine, 35 Shinanomachi, Shinjuku-ku, Tokyo 160-8582, Japan; ${ }^{3}$ Department of Preventive Medicine and Public Health, Keio University School of Medicine, 35 Shinanomachi, Shinjuku-ku, Tokyo 160-8582, Japan and ${ }^{4}$ Hepato-Biliary-Pancreatic and Gastrointestinal Surgery, International University of Health and Welfare School of Medicine, 14-1-6 Kokufudai Ichikawa-shi, Chiba 272-0827, Japan

Background: Pancreatic ductal adenocarcinoma (PDAC) has very poor prognosis despite existing multimodal therapies. This study aimed to investigate whether KRAS mutations at codons 12/13 in cell-free DNA (cfDNA) from preoperative and postoperative sera from patients with PDAC can serve as a predictive biomarker for treatment response and outcomes after surgery.

Methods: Preoperative and postoperative serum samples obtained from 45 patients with PDAC whom underwent curative pancreatectomy at our institution between January 2013 and July 2016 were retrospectively analysed. Peptide nucleic aciddirected PCR clamping was used to identify KRAS mutations in cfDNA.

Results: Among the 45 patients enrolled, 11 (24.4\%) and 20 (44.4\%) had KRAS mutations in cfDNA from preoperative and postoperative sera, respectively. Multivariate analysis revealed that KRAS mutations in postoperative serum (hazard ratio $(H R)=2.919 ; 95 \%$ confidence interval $(C I)=1.109-5.621 ; P=0.027)$ are an independent prognostic factor for disease-free survival. Furthermore, the shift from wild-type KRAS in preoperative to mutant KRAS in postoperative cfDNA $(\mathrm{HR}=9.419 ; 95 \% \mathrm{Cl}=2.015-$ 44.036; $P=0.004)$ was an independent prognostic factor for overall survival.

Conclusions: Changes in KRAS mutation status between preoperative and postoperative cfDNA may be a useful predictive biomarker for survival and treatment response.

Pancreatic ductal adenocarcinoma (PDAC) is a lethal malignancy characterised by rapid progression and poor prognosis. The disease is associated with a 5 -year survival rate of $<10 \%$, which is mainly attributable to aggressive tumour behaviour and late clinical detection (Siegel et al, 2016).
Most of the patients with PDAC carry mutations in the KRAS gene, which encodes a member of the RAS family of GTPases. KRAS mutations have been identified in $67.4 \%$ and $79.3 \%$ of formalin-fixed paraffin-embedded (FFPE) and fresh-frozen tumour samples, respectively, and in $40.8 \%$ of plasma/serum

*Correspondence: Dr M Kitago; E-mail: dragonpegasus@keio.jp

Received 20 June 2017; revised 3 December 2017; accepted 4 December 2017; published online 23 January 2018

(C) 2018 Cancer Research UK. All rights reserved 0007 - 0920/18 
samples (Li et al, 2016). KRAS mutation status in various patient tissues has been identified as a prognostic biomarker for PDAC outcome ( $\mathrm{Li}$ et al, 2016). Liquid biopsy is considered a helpful non-invasive test for early-stage cancer diagnosis and for the assessment of treatment responses to chemotherapy or surgery (Mori et al, 2005; Shinozaki et al, 2007; Schwarzenbach et al, 2011).

Nucleic acids are released into the blood circulation upon cell apoptosis or necrosis (Earl et al, 2015). Accordingly, increased cell turnover owing to rapid tumour progression, necrosis, and apoptosis leads to elevated levels of cell-free DNA (cfDNA) (Schwarzenbach et al, 2011). Liquid biopsy is a minimally invasive technology to reveal molecular biomarkers in the peripheral blood, using mostly circulating tumour (ctDNA) and circulating tumour cells (CTCs) (Mori et al, 2005; Shinozaki et al, 2007; Schwarzenbach et al, 2011). Liquid biopsy analysis of cfDNA, ctDNA, and CTCs from plasma or serum of cancer patients, including those with PDAC, has been widely used to detect cancer-related mutations, for early detection of disease progression, and/or for monitoring treatment response to chemotherapy (Mori et al, 2005; Shinozaki et al, 2007; Kitago et al, 2009; Earl et al, 2015; Takai et al, 2015; Gao et al, 2016). For example, Diehl et al (2008) reported that ctDNA is a promising source of biomarkers to follow the therapeutic course in patients with metastatic colorectal cancer, showing that patients who had detectable ctDNA after surgery generally relapsed within 1 year. The frequency of CTC detection in PDAC is generally very low (Allard et al, 2004), and owing to advances in DNA extraction and PCR technologies, ctDNA is more clinically useful than CTCs (Cabel et al, 2017). Although several retrospective studies have reported the utility of KRAS mutations in cfDNA from patients with PDAC (Earl et al, 2015; Takai et al, 2015), it remains unclear whether changes in the KRAS mutation rate between preoperative and postoperative sera can be used as an indicator for treatment responses in PDAC.

Therefore, in this study, we analysed the KRAS mutation status in cfDNA from preoperative and postoperative serum samples to determine whether it can serve as a biomarker to monitor the treatment response of patients with PDAC after curative resection and to predict disease outcome. The mutation status of the primary tumour was determined using FFPE tissue samples.

\section{MATERIALS AND METHODS}

Patients. Patients who underwent curative pancreatectomy for PDAC at our institution between January 2013 and July 2016 were retrospectively analysed. All patients were histologically proven to have invasive ductal carcinoma. Patients who had undergone R2 operation and for whom preoperative and postoperative serum samples had not been collected were excluded. Patients with or without KRAS mutations identified in preoperative and postoperative sera were divided into four groups according to the pattern of KRAS mutations. Group 1 included patients with wildtype KRAS (wtKRAS) in both preoperative and postoperative sera (pre ${ }^{-} /$post $^{-}$), Group 2 included patients with wtKRAS in preoperative but mutant KRAS (mtKRAS) in postoperative sera (pre $^{-} /$post $^{+}$), Group 3 comprised patients with mtKRAS in preoperative but wtKRAS in postoperative sera $\left(\mathrm{pre}^{+} / \mathrm{post}^{-}\right)$, and Group 4 included patients with $\mathrm{mtKRAS}$ both in preoperative and postoperative sera ( pre $^{+} /$post $^{+}$). All participants provided written informed consent. The study was approved by the Human Experimentation Committee of our institution and was conducted in accordance with the Helsinki Declaration of 1975. The trial was registered with the University Hospital Medical Information
Network (UMIN) Clinical Trials Registry (http://www.umin.ac.jp/ctr/number: UMIN-000014691).

Clinicopathological characteristics. Preoperative clinical variables included age, sex, presence of diabetes mellitus, family history of cancer, treatment with neo-adjuvant chemoradiotherapy (NACRT), and surgical procedure. Postoperative variables included operation time, blood loss, and complications evaluated according to Clavien-Dindo classification. In our institution, some patients diagnosed with T3 or T4 disease according to the Seventh edition of the Union for International Cancer Control (UICC) TNM classification of malignant tumours have been receiving NACRT since 2003 (Fujii-Nishimura et al, 2015). In addition, perioperative portal vein infusion (PVI) chemotherapy on the day of surgery has been performed since 1984 as a standard treatment to prevent liver metastasis and to improve the survival of patients subjected to potentially curative resection of pancreatic cancer (Takahashi et al, 1999; Aiura et al, 2010).

The pathologic stage of residual tumours (R) was determined according to the Seventh edition of the UICC TNM classification. $\mathrm{R} 0$ resections showed no tumour residues, R1 resections showed microscopically positive margins, and R2 resections still showed some gross tumours. Prognostic pathological features assessed by histology included tumour size, distal bile-duct invasion, duodenal invasion, serosal invasion, retropancreatic tissue invasion, portal vein invasion, arterial invasion, extrapancreatic nerve plexus invasion, invasion of other organs, lymph node metastasis, lymphatic infiltration, venous infiltration, and intrapancreatic nerve infiltration (Kanehara, 2009).

Preparation of and DNA extraction from FFPE tissue samples. Resected specimens were immediately fixed in $10 \%$ buffered formalin. The fixed specimens were serially sectioned $(5-\mathrm{mm}$ thickness) and embedded in paraffin within 1 week using routine methods. The paraffin sections were stained with haematoxylin and eosin. After the slides from each individual patient were reviewed, the main tumour lesion was designated by a surgical pathologist.

Ten-micrometre sections of the primary tumour were cut from each block and placed on glass slides. One section of the main tumour was stained with haematoxylin and eosin for orientation, which was confirmed by a surgical pathologist. Tiny fractions of the main tumour lesions were dissected from the $10-\mu \mathrm{m}$ sections macroscopically, and fractions from two or three sections were collected in sterile tubes. DNA was extracted and purified from these paraffin sections using the QIAamp DNA FFPE Tissue Kit (Qiagen, Hilden, Germany) (Kitago et al, 2004).

Serum sample collection. Preoperative serum samples were collected 1 day before operation or on the day of operation. Postoperative serum samples were obtained before discharge from the hospital if patients showed no signs of inflammation, such as fever and elevated levels of inflammatory indicators in laboratory tests. Twelve-millilitre blood samples were collected in Venoject II tubes (Terumo, Tokyo, Japan) and were processed immediately. To separate serum from peripheral blood cells, samples were centrifuged at $1750 \mathrm{~g}$ at $21^{\circ} \mathrm{C}$ for $10 \mathrm{~min}$, and the serum was stored at $-80^{\circ} \mathrm{C}$

DNA extraction from serum. cfDNA was extracted from serum using the Plasma/Serum Cell-Free Circulating DNA Purification Midi Kit (Norgen Biotek, Thorold, Ontario, Canada) according to the manufacturer's instructions. This method employs a twocolumn method for the isolation of high-quality, high-purity, and inhibitor-free cfDNA from fresh or frozen plasma/serum samples. Briefly, $1-4 \mathrm{ml}$ of serum was used as an input volume on the first column to extract cfDNA, which was concentrated on the second 
mini column into a final elution volume of $30 \mu \mathrm{l}$. The cfDNA obtained was stored at $-80^{\circ} \mathrm{C}$.

Quantification of genomic DNA in FFPE and serum samples. Gene dosage analysis was conducted by real-time quantitative PCR (qPCR) using the TaqMan RNase P Detection Reagents Kit (Applied Biosystems, Carlsbad, CA, USA). The reaction was carried out in a total volume of $20 \mu \mathrm{l}$, including $2 \mathrm{ng}$ of sample DNA, $1 \mu \mathrm{l}$ of RNase P Detection Reagents $(20 \times)$ containing primers and probe (Applied Biosystems FAM, dye-labelled with TAMRA quencher), and $8 \mu \mathrm{l}$ of sterile water. The thermal cycling conditions were as follows: $50{ }^{\circ} \mathrm{C}$ for $2 \mathrm{~min}, 95^{\circ} \mathrm{C}$ for $10 \mathrm{~min}$, and 45 cycles of $95^{\circ} \mathrm{C}$ for $15 \mathrm{~s}$ and $60^{\circ} \mathrm{C}$ for $1 \mathrm{~min}$. Each sample was assayed in duplicate in the Viia7 Real-Time PCR System (Applied Biosystems). Healthy male genomic DNA was used as a calibration standard.

Primers and probes for peptide nucleic acid (PNA)-directed PCR clamping. Because cfDNA mtKRAS is present in very small copy numbers and is difficult to identify among thousands of wtKRAS copies, we used the PNA method to inhibit amplification of excess non-target DNA (Taback et al, 2004; Kim et al, 2006). PNA is a synthetic nucleic acid polymer that binds the wtKRAS allele surrounding codons $12 / 13$ and inhibits the annealing of the reverse primer, thus blocking fragment amplification. PNAdirected PCR clamping is more efficient for detecting KRAS mutations at codons 12/13 than other methods, such as direct sequencing (Taback et al, 2004; Kim et al, 2006; Araki et al, 2010; Han et al, 2016). DNA was amplified by qPCR using the following primers: KRAS, 5'-GGCCTGCTGAAAATGA-3' (forward) and 5' AAGGCACTCTTGCCTA-3' (reverse). The sequences of the FRET probe and PNA were $5^{\prime}$-FAM-AGCTCCAACTACCACAAGTTTATATTC-BHQ-1-3' and 5'-TACGCCACCAGCTCC-3', respectively. Genomic DNA (2 ng) was amplified in a $25-\mu$ l reaction containing $1 \mu \mathrm{M}$ of each primer, $1 \mu \mathrm{M}$ of probe, $1.75 \mu \mathrm{M}$ of PNA, and $12.5 \mu \mathrm{l}$ of TaqMan gene expression master mix (Applied Biosystems). PCR was carried out in the Viia7 Real-Time PCR System using the following temperature conditions: 40 cycles at $94{ }^{\circ} \mathrm{C}$ for $60 \mathrm{~s}, 70^{\circ} \mathrm{C}$ for $50 \mathrm{~s}$, and $58^{\circ} \mathrm{C}$ for $50 \mathrm{~s}$, and a final extension at $72{ }^{\circ} \mathrm{C}$ for $60 \mathrm{~s}$. Reactions were also conducted without PNA to amplify wtKRAS and to verify DNA integrity. Each sample was assayed in duplicate with positive and negative controls.

Cell lines. To assess the accuracy and sensitivity of PNA-directed PCR clamping, we analysed four pancreatic cancer cell lines. AsPC1 and Capan-1 containing mtKRAS and BxPC-3 and Hs 700T containing wtKRAS were obtained from the American Type Culture Collection (Manassas, VA, USA) and were cultured as recommended. PCR was conducted using 0.2 and $2 \mathrm{ng}$ of genomic DNA as a template.

Statistical analysis. Statistical analysis was conducted using IBM SPSS statistics version 23.0 (IBM Japan, Tokyo, Japan). Clinicopathological features were compared between patients with and without KRAS mutations in postoperative sera and between the four groups with different KRAS mutation status in preoperative and postoperative sera. Categorical variables were compared by the chi-square or Fisher exact test and continuous variables were compared by the Mann-Whitney $U$-test with Bonferroni's correction for multiple comparisons. Correlation between early recurrence ( $\leqslant 6$ months) and cfDNA KRAS mutation status was analysed using Cohen's kappa statistics. Survival duration was calculated according to the Kaplan-Meier method, and survival curves were compared by the Wilcoxon test. A Cox proportional hazards model was used to determine independent prognostic factors among preoperative and postoperative variables. The stepwise method was used for multivariate analysis.

\section{RESULTS}

Validation of the PNA clamp PCR assay. The sensitivity and accuracy of the PNA clamp method for the detection of KRAS mutation have been previously established (Taback et al, 2004; Kim et al, 2006). To validate the sensitivity of the PNA quantitative realtime PCR assay in our current study, AsPC-1 DNA was mixed with Hs 700T DNA at different ratios: 1:10, 1:100, and 1:1000, and the PNA clamp PCR assay was carried out using 2 ng of DNA from the each of the mixtures. KRAS mutation could be detected at a mutant-to-wild-type DNA ratio of 1:1000. To assay the accuracy, sequence analysis was conducted for 10 primary tumours found to be either KRAS-positive $(n=7)$ or KRAS-negative $(n=3)$ by PNA clamp PCR. Except for one sample, direct sequencing of the PCR product confirmed the presence or absence of mutation as detected by PNA clamp PCR, and the KRAS mutation status of these samples as determined by PNA clamp PCR was consistent with the results of direct sequencing.

Detection of KRAS mutations in pancreatic cancer cell lines and sera of healthy donors. The results of PNA-directed PCR clamping applied to cancer cell lines and sera of cancer-free donors indicated that a sample could be considered positive for KRAS mutations if the $C_{\mathrm{t}}$ number was $<35$ when $2 \mathrm{ng}$ cfDNA was used.

Patient characteristics and KRAS mutation status. In total, 84 patients underwent curative pancreatectomy in our hospital between January 2013 and July 2016. Thirty-nine patients were excluded because of incomplete preoperative and postoperative serum samples; the remaining 45 patients were enrolled in the study. Clinicopathological characteristics of the 45 patients are presented in Table 1, and characteristics of patients with wtKRAS and $\mathrm{mtKRAS}$ in postoperative serum are shown in Table 2. KRAS mutations of FFPE were detected in 35 of 42 (83.3\%) primary tumours. For three patients, we were unable to determine KRAS mutation status. cfDNA KRAS mutations were detected in 11 (24.4\%) preoperative and $20(44.4 \%)$ postoperative samples.

The 45 patients were divided into four groups based on the presence of KRAS mutations in preoperative and postoperative sera: 20 patients $(44.4 \%)$ were assigned to Group 1 (pre $^{-} /$post $^{-}$), $14(31.1 \%)$ to Group $2\left(\right.$ pre $^{-} /$post $\left.^{+}\right), 5(11.1 \%)$ to Group 3 (pre ${ }^{+} /$ post $\left.^{-}\right)$, and $6(13.3 \%)$ to Group 4 (pre $^{+} /$post $\left.^{+}\right)$. Clinicopathological characteristics of patients in the four groups are shown in Table 3.

Association of KRAS mutations in preoperative and postoperative sera with survival. There were no significant differences in disease-free survival (DFS) and overall survival (OS) between patients with and without KRAS mutations in cfDNA from preoperative serum. However, patients with $\mathrm{mtKRAS}$ in postoperative cfDNA showed significantly shorter DFS $(P=0.014$; Figure $1 \mathrm{~A})$ and $\mathrm{OS}(P=0.044$; Figure $1 \mathrm{~B})$ than those with wtKRAS.

Survival curve analysis did not reveal significant differences in DFS (Figure 2A) and OS (Figure 2B) among the groups. However, pair-wise comparison showed that patients in Group 2 (pre ${ }^{-}$/ post $^{+}$) had significantly shorter DFS than those in Group 1 (pre ${ }^{-}$/ post $\left.^{-}\right)(P=0.022$; Figure $2 \mathrm{C})$, although no difference in OS $(P=0.071$; Figure $2 \mathrm{D})$ was observed.

In total, $8(17.8 \%)$ patients had early recurrence ( $\leqslant 6$ months), and correlation analysis revealed a significant association between early recurrence and KRAS mutations in postoperative cfDNA $(\kappa=0.426 ; P<0.001)$. At the same time, positive and negative correlations with early recurrence were detected in Group 1 (pre ${ }^{-} /$ post $\left.^{-}\right) \quad(\kappa=0.295 ; \quad P=0.049)$ and Group $2 \quad\left(\right.$ pre $^{-} /$post $\left.^{+}\right)$ $(\kappa=-0.340 ; P=0.005)$, respectively. 
Table 1. Clinicopathological characteristics of PDAC patients enrolled in the study $(n=45)$

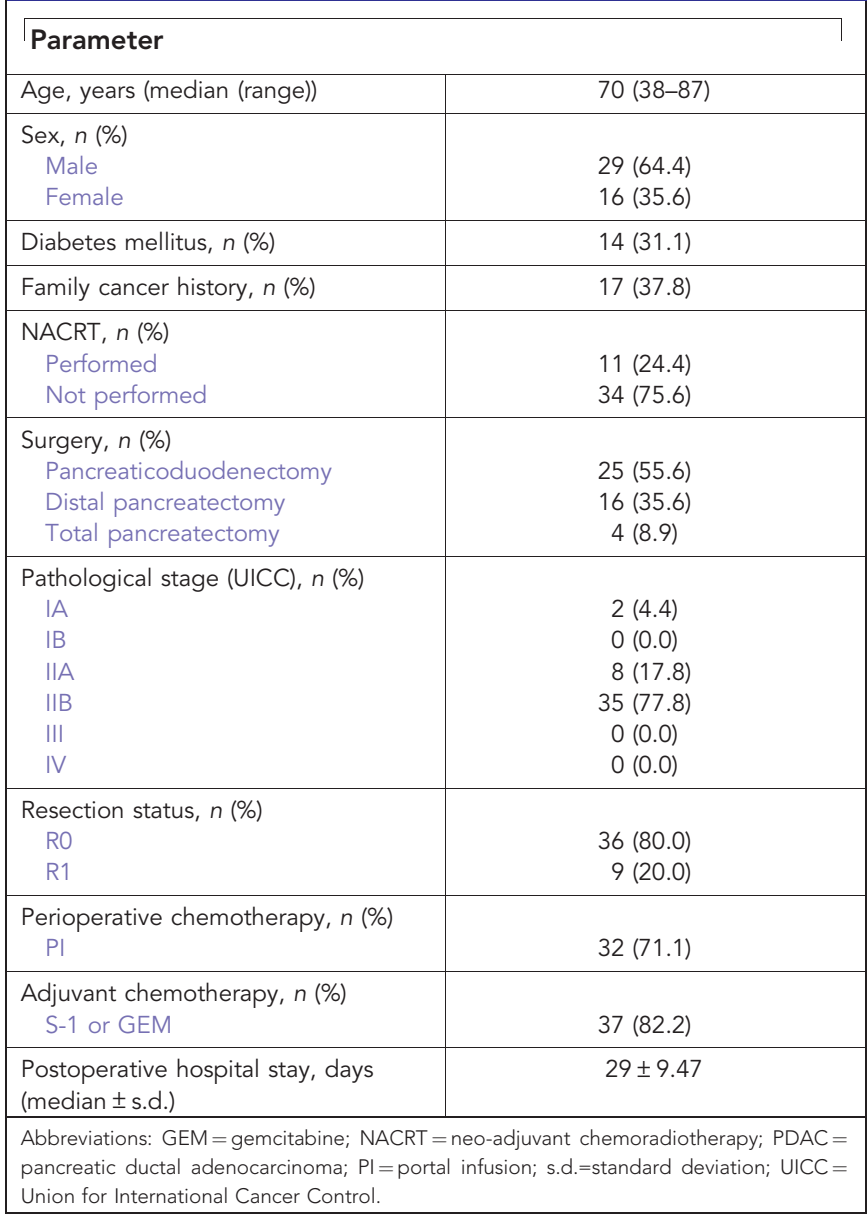

Univariate analysis of DFS and OS identified venous, serosal, and retropancreatic tissue invasions as significant prognostic factors for poor DFS, whereas the change from wtKRAS in preoperative serum to mtKRAS in postoperative serum (Group 2, pre $^{-} /$post $^{+}$) was a prognostic factor for poor OS (Table 4A). Multivariate analysis revealed that serosal invasion (hazard ratio $(\mathrm{HR})=3.919 ; \quad 95 \% \quad$ confidence interval $\quad(\mathrm{CI})=1.650-9.311$; $P=0.002$ ) and KRAS mutations in postoperative cfDNA (post ${ }^{+}$) $(\mathrm{HR}=2.919 ; 95 \% \mathrm{CI}=1.109-5.612 ; P=0.027)$ were independent prognostic factors for poor DFS, whereas neural infiltration $(\mathrm{HR}=0.197 ; 95 \% \mathrm{CI}=0.044-0.876 ; P=0.033)$ and Group 2 cfDNA genotype $\left(\mathrm{pre}^{-} /\right.$post $\left.^{+}\right)(\mathrm{HR}=9.419 ; 95 \% \mathrm{CI}=2.015-$ 44.036; $P=0.004$ ) were independent prognostic factors for poor OS (Table 4B).

\section{DISCUSSION}

The present study investigated whether KRAS mutations in cfDNA from serum samples taken before and after curative surgery could be a prognostic factor in patients with PDAC. To the best of our knowledge, this study was the first to focus on changes in the KRAS mutation status between cfDNA from preoperative and postoperative sera. As a result, we identified the shift from wtKRAS before curative resection to mtKRAS after resection as an independent biomarker for poor OS in PDAC patients. Moreover, serosal invasion and KRAS mutations in cfDNA from postoperative serum were significant independent prognostic
Table 2. Clinicopathological characteristics of patients with and without KRAS mutations in postoperative serum

KRAS mutation status in postoperative serum

\begin{tabular}{|c|c|c|c|}
\hline Parameter & $\begin{array}{c}\text { Negative } \\
(n=25)\end{array}$ & $\begin{array}{l}\text { Positive } \\
(n=20)\end{array}$ & $P$ \\
\hline Age, years (median (range)) & $70(38-80)$ & $70(48-87)$ & 0.672 \\
\hline $\begin{array}{l}\text { Sex, } n(\%) \\
\quad \text { Male } \\
\text { Female }\end{array}$ & $\begin{array}{r}17(68.0) \\
8(32.0)\end{array}$ & $\begin{array}{r}12(60.0) \\
8(40.0)\end{array}$ & 0.403 \\
\hline Diabetes mellitus, $n(\%)$ & $6(24.0)$ & $8(40.0)$ & 0.204 \\
\hline Family cancer history, n (\%) & $10(40.0)$ & $7(35.0)$ & 0.487 \\
\hline $\begin{array}{l}\text { Procedure, } n(\%) \\
\text { Pancreaticoduodenectomy } \\
\text { Distal pancreatectomy } \\
\text { Total pancreatectomy }\end{array}$ & $\begin{array}{r}16(64.0) \\
6(24.0) \\
3(12.0)\end{array}$ & $\begin{aligned} 9 & (45.0) \\
10 & (50.0) \\
1 & (5.0)\end{aligned}$ & 0.178 \\
\hline $\begin{array}{l}\text { NACRT, n (\%) } \\
\text { Performed }\end{array}$ & $8(32.0)$ & $3(15.0)$ & 0.167 \\
\hline $\begin{array}{l}\text { Resection status, n (\%) } \\
\quad \text { R0 } \\
\text { R1 }\end{array}$ & $\begin{array}{r}21(84.0) \\
4(16.0) \\
\end{array}$ & $\begin{array}{r}15(75.0) \\
5(25.0) \\
\end{array}$ & 0.352 \\
\hline $\begin{array}{l}\text { Lymph node metastasis, n (\%) } \\
\text { N0 } \\
\text { N1 }\end{array}$ & $\begin{array}{r}5(20.0) \\
20(80.0)\end{array}$ & $\begin{array}{r}5(25.0) \\
15(75.0)\end{array}$ & 0.481 \\
\hline $\begin{array}{l}\text { Stage (UICC), n (\%) } \\
\text { IA } \\
\text { IB } \\
\text { IIA } \\
\text { IIB } \\
\text { III } \\
\text { IV }\end{array}$ & $\begin{aligned} 2 & (8.0) \\
0 & (0.0) \\
3 & (12.0) \\
20 & (80.0) \\
0 & (0.0) \\
0 & (0.0)\end{aligned}$ & $\begin{array}{c}0(0.0) \\
0(0.0) \\
5(25.0) \\
15(75.0) \\
0(0.0) \\
0(0.0)\end{array}$ & 0.260 \\
\hline $\begin{array}{l}\text { Perioperative chemotherapy, } n(\%) \\
\text { PI }\end{array}$ & $19(76.0)$ & $13(72.7)$ & 0.315 \\
\hline $\begin{array}{l}\text { Adjuvant chemotherapy, } n \text { (\%) } \\
\text { S-1 or GEM }\end{array}$ & $20(80.0)$ & $16(72.7)$ & 0.642 \\
\hline $\begin{array}{l}\text { First recurrence region } \\
\text { Liver } \\
\text { Lung } \\
\text { Peritoneal } \\
\text { Local } \\
\text { Lymph node }\end{array}$ & $\begin{array}{l}3(12.0) \\
2(8.0) \\
1(4.0) \\
3(12.0) \\
0(0.0)\end{array}$ & $\begin{array}{l}4(20.0) \\
4(20.0) \\
4(20.0) \\
2(10.0) \\
0(0.0)\end{array}$ & $\begin{array}{l}0.229 \\
0.131 \\
0.126 \\
0.553\end{array}$ \\
\hline
\end{tabular}

Abbreviations: GEM = gemcitabine; NACRT = neo-adjuvant chemoradiotherapy; $\mathrm{PI}=$ portal infusion; UICC $=$ Union for International Cancer Control.

factors for poor DFS, whereas neural infiltration and changes in the KRAS mutation status between preoperative and postoperative serum cfDNA ( $\mathrm{pre}^{-} /$post $^{+}$) were significant independent prognostic factors for dismal OS. The presence of KRAS mutations in postoperative cfDNA and a change from mutationnegative to mutation-positive status showed significant positive correlation with early recurrence ( $\leqslant 6$ months), whereas the consistent mutation-negative state had a significant negative correlation with early recurrence. Thus these parameters are potentially useful predictive biomarkers of early recurrence and effects of therapeutic intervention after surgery. Moreover, in view of adjuvant chemotherapy after surgery, regular monitoring of the KRAS mutation status in postoperative cfDNA may be used to determine whether the regimen should be continued or changed.

The shift from mtKRAS-negative to -positive status in cfDNA after surgery is puzzling. Possible reasons may be tumour manipulation during surgery and/or cell/DNA release from residual or potentially metastatic tumours. This notion is supported by studies showing that manipulations during pancreaticoduodenectomy might contribute to the release of CTCs to the 
Table 3. Clinicopathological characteristics of patients in the four groups

\begin{tabular}{|c|c|c|c|c|c|}
\hline Parameter & $\begin{array}{l}\text { Group } 1\left(\text { pre }^{-} /\right. \\
\left.\text {post }^{-}\right)(n=20)\end{array}$ & $\begin{array}{l}\text { Group } 2\left(\text { pre }^{-} /\right. \\
\left.\text {post }^{+}\right)(n=14)\end{array}$ & $\begin{array}{c}\text { Group } 3\left(\text { pre }^{+} /\right. \\
\left.\text {post }^{-}\right)(n=5)\end{array}$ & $\begin{array}{c}\text { Group } 4\left(\text { pre }^{+} /\right. \\
\left.\text {post }^{+}\right)(n=6)\end{array}$ & $P$ \\
\hline Age, years (median (range)) & $71(58-82)$ & $72(48-85)$ & $61(38-71)$ & $67(57-87)$ & 0.927 \\
\hline $\begin{array}{l}\text { Sex, } n(\%) \\
\text { Male } \\
\text { Female }\end{array}$ & $\begin{array}{r}13(44.8) \\
7(43.8)\end{array}$ & $\begin{array}{l}7(24.1) \\
7(43.8)\end{array}$ & $\begin{array}{l}4(13.8) \\
1(6.3)\end{array}$ & $\begin{array}{l}5(17.2) \\
1(6.3)\end{array}$ & 0.434 \\
\hline Diabetes mellitus, $n(\%)$ & $5(35.7)$ & $4(28.6)$ & $1(7.1)$ & $4(28.6)$ & 0.239 \\
\hline $\begin{array}{l}\text { NACRT, } n(\%) \\
\text { Performed }\end{array}$ & $5(45.5)$ & $2(18.2)$ & $3(27.3)$ & $1(9.1)$ & 0.221 \\
\hline $\begin{array}{l}\text { Resection status, n (\%) } \\
\text { R0 } \\
\text { R1 }\end{array}$ & $\begin{array}{r}17(47.2) \\
3(33.3)\end{array}$ & $\begin{array}{r}11(30.6) \\
3(33.3)\end{array}$ & $\begin{array}{l}4(11.1) \\
1(11.1)\end{array}$ & $\begin{array}{l}4(11.1) \\
2(22.2)\end{array}$ & 0.802 \\
\hline $\begin{array}{l}\text { Pathological stage (UICC), } n \text { (\%) } \\
\text { IA } \\
\text { IB } \\
\text { IIA } \\
\text { IIB } \\
\text { III } \\
\text { IV }\end{array}$ & $\begin{array}{c}1(50.0) \\
0(0.0) \\
3(37.5) \\
16(45.7) \\
0(0.0) \\
0(0.0)\end{array}$ & $\begin{array}{c}0(0.0) \\
0(0.0) \\
1(12.5) \\
13(37.1) \\
0(0.0) \\
0(0.0)\end{array}$ & $\begin{array}{l}1(50.0) \\
0(0.0) \\
0(0.0) \\
4(11.4) \\
0(0.0) \\
0(0.0)\end{array}$ & $\begin{array}{l}0(0.0) \\
0(0.0) \\
4(50.0) \\
2(5.7) \\
0(0.0) \\
0(0.0)\end{array}$ & 0.008 \\
\hline $\begin{array}{l}\text { Perioperative chemotherapy, } n(\%) \\
\text { PI }\end{array}$ & $15(46.9)$ & $9(28.1)$ & $4(12.5)$ & $4(12.5)$ & 0.870 \\
\hline $\begin{array}{l}\text { Adjuvant chemotherapy, } n \text { (\%) } \\
\text { S-1 or GEM }\end{array}$ & 16 (44.4) & 12 (33.3) & $4(11.1)$ & $4(11.1)$ & 0.813 \\
\hline
\end{tabular}

portal circulation (Hirota et al, 2010; Gall et al, 2014), whereas during distal pancreatectomy with the no-touch technique, cancer cells were not observed in the portal vein (Hirota et al, 2005). In this study, the incidence of postoperative mtKRAS was higher among patients with distal pancreatectomy than among those with pancreaticoduodenectomy; however, the difference was not significant, suggesting that the emergence of $m t K R A S$-positive cfDNA may not be due to tumour manipulation during pancreatectomy. According to Diehl et al (2008), postoperative ctDNA levels in patients with an incomplete resection did not decrease after surgery. Instead, postoperative ctDNA levels in some patients were higher than preoperative levels because the injury to the remaining tumour tissue during surgery caused DNA release. In our study, postoperative mtKRAS was more prevalent than wtKRAS in patients with $\mathrm{R} 1$ resection, although the difference was not significant. Another conceivable reason for the appearance of KRAS mutations after surgery may be the presence of potentially metastatic tumours undetected by preoperative imaging that released CTCs and ctDNA. However, the contribution of the above-mentioned factors to the pre ${ }^{-} /$post $^{+} \mathrm{mtKRAS}$ shift remains unclear, and further genetic and biochemical studies are required to disclose mechanisms underlying changes in the cfDNA profile after curative resection.
Because the half-lives of cfDNA and ctDNA after surgery are quite short (Lo et al, 1999; Diehl et al, 2008), the reverse change, that is, from mtKRAS to wtKRAS, may be an indication of a positive outcome. Although the follow-up period in the pre $^{+} /$ post $^{-}$group was shorter than that in the other groups, the prognosis was better. On the other hand, the presence of KRAS mutations in both preoperative and postoperative cfDNA may indicate a lack of clinical response to surgery and chemotherapy, such as NACRT or perioperative PVI.

Our study had several limitations. First, we conducted a retrospective analysis using a small number of patients from a single institution. Second, for some NACRT-treated patients, blood samples had not been collected before NACRT, and it was unclear whether NACRT had an effect on KRAS mutations in cfDNA. Prospective studies are needed to confirm our preliminary findings and to evaluate the association between changes in the mtKRAS status in cfDNA in PDAC patients and both short- and long-term responses to treatment, including chemotherapy (NACRT, PVI, and adjuvant chemotherapy) after surgery.

In conclusion, this pilot study showed that changes in the KRAS mutation status of cfDNA might have potential clinical utility as a biomarker for monitoring treatment response and predicting survival and early recurrence ( $\leqslant 6$ months) in PDAC. Such an 

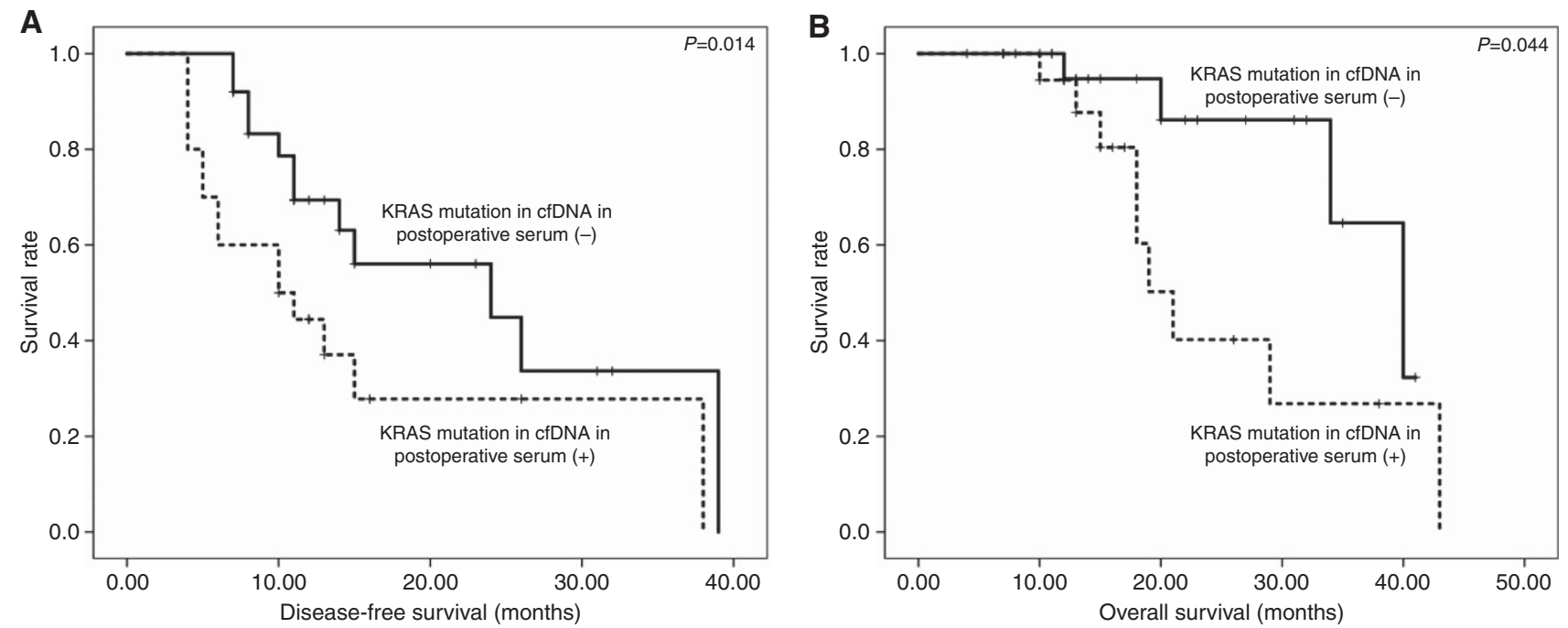

Figure 1. Correlation of KRAS mutations in cfDNA from postoperative serum with postoperative survival of PDAC patients. KRAS mutations in postoperative cell free DNA (cfDNA) significantly correlated with disease-free survival (A) and overall survival (B).
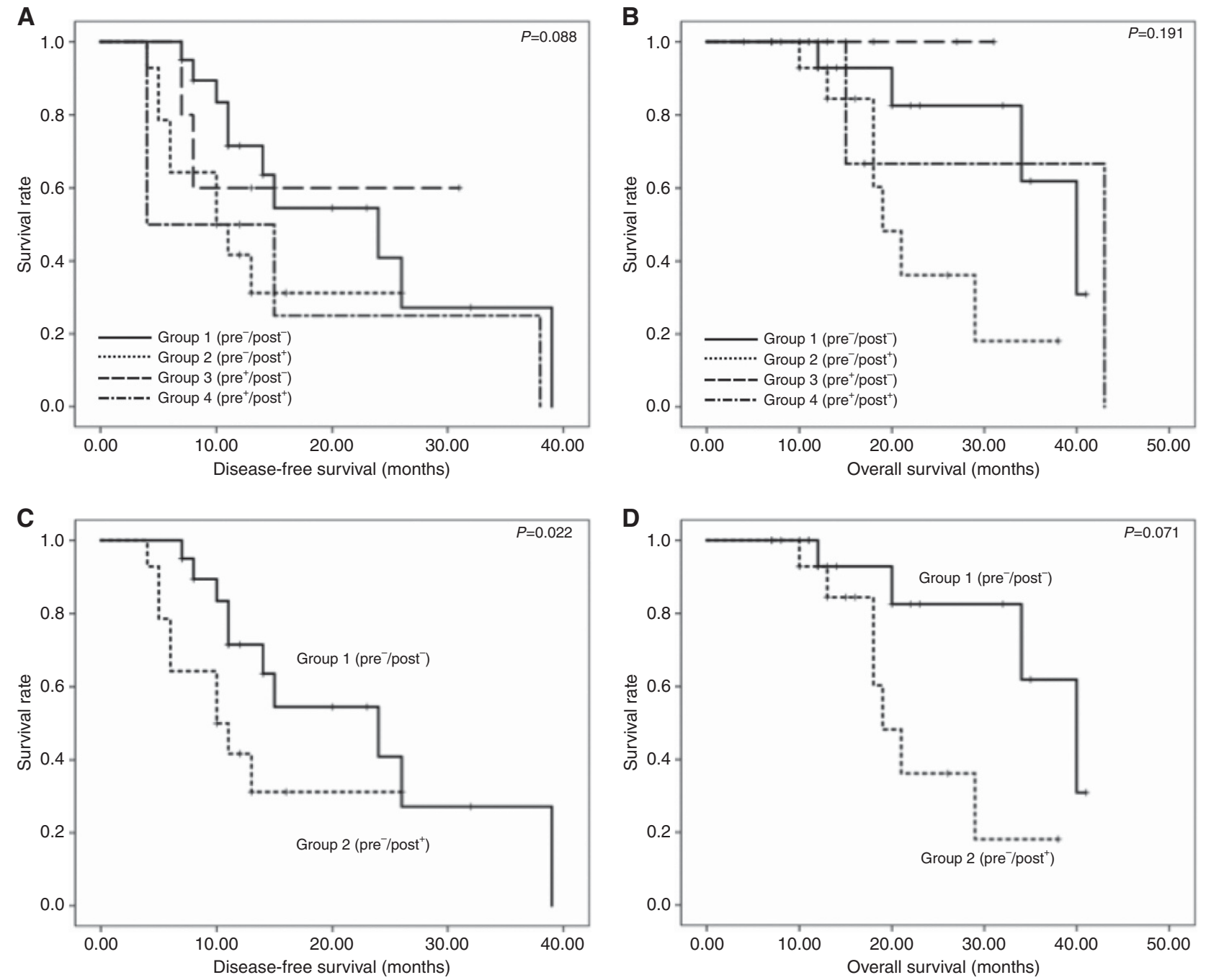

Figure 2. Correlation of the KRAS mutation status in cfDNA with postoperative survival. (A, B) Comparison of disease-free survival (DFS) (A) and overall survival (OS) (B) among the four groups of PDAC patients carrying KRAS mutations in preoperative and/or postoperative cfDNA. No significant difference was observed in DFS (A) and OS (B) between the four groups. (C, D) Comparison of DFS (C) and OS (D) between patients with wtKRAS (pre ${ }^{-} /$post $^{-}$) and those shifted to the KRAS mutation status after surgery (pre ${ }^{-} /$post $^{+}$). 
Table 4A. Univariate analysis of clinicopathological variables in relation to disease-free and overall survival

Disease-free survival

\begin{tabular}{|c|c|c|c|c|c|c|}
\hline Factor & $P$ & Hazard ratio & $95 \% \mathrm{Cl}$ & $P$ & Hazard ratio & $95 \% \mathrm{Cl}$ \\
\hline Age $\geqslant 70$ years & 0.094 & 0.502 & $0.224-1.125$ & 0.504 & 0.673 & $0.211-2.148$ \\
\hline Sex (male) & 0.844 & 0.921 & $0.404-2.101$ & 0.258 & 0.520 & $0.167-1.616$ \\
\hline Diabetes mellitus $(+)$ & 0.235 & 1.631 & $0.727-3.659$ & 0.807 & 1.157 & $0.358-3.740$ \\
\hline Family cancer history $(+)$ & 0.701 & 0.844 & $0.356-2.001$ & 0.079 & 0.291 & $0.073-1.154$ \\
\hline $\operatorname{NACRT}(+)$ & 0.338 & 0.591 & $0.202-1.732$ & 0.970 & 0.975 & $0.262-3.626$ \\
\hline Perioperative Adjuvant (PI) (+) & 0.805 & 1.117 & $0.464-2.688$ & 0.910 & 0.926 & $0.248-3.465$ \\
\hline Operative time $\geqslant 450 \mathrm{~min}$ & 0.720 & 1.159 & $0.518-2.592$ & 0.185 & 2.272 & $0.675-7.644$ \\
\hline Amount of bleeding $\geqslant 310 \mathrm{~g}$ & 0.608 & 1.237 & $0.548-2.792$ & 0.742 & 1.230 & $0.358-4.226$ \\
\hline Complication (Clavien-Dindo $\geqslant \mid l l a)(+)$ & 0.717 & 0.817 & $0.272-2.437$ & 0.569 & 0.640 & $0.138-2.967$ \\
\hline Lymphatic infiltration (0 or 1$)$ & 0.127 & 0.503 & $0.208-1.215$ & 0.432 & 0.613 & $0.181-2.074$ \\
\hline Venous infiltration ( 0 or 1 ) & 0.022 & 0.270 & $0.088-0.829$ & 0.599 & 0.719 & $0.211-2.452$ \\
\hline Neural infiltration (0 or 1$)$ & 0.271 & 0.621 & $0.266-1.451$ & 0.353 & 0.567 & $0.172-1.875$ \\
\hline Serosal invasion $(+)$ & 0.004 & 3.474 & $1.487-8.117$ & 0.138 & 2.555 & $0.741-8.813$ \\
\hline Retropancreatic tissue invasion $(+)$ & 0.036 & 4.730 & $1.107-20.219$ & 0.467 & 1.760 & $0.384-8.072$ \\
\hline Distal bile duct invasion $(+)$ & 0.443 & 0.709 & $0.295-1.708$ & 0.313 & 0.509 & $0.137-1.890$ \\
\hline Duodenal invasion $(+)$ & 0.981 & 0.990 & $0.451-2.175$ & 0.102 & 0.364 & $0.109-1.223$ \\
\hline Extrapancreatic nerve plexus invasion $(+)$ & 0.988 & 1.008 & $0.375-2.713$ & 0.592 & 1.444 & $0.367-5.545$ \\
\hline Vascular invasion & 0.301 & 1.524 & $0.686-3.385$ & 0.322 & 1.799 & $0.562-5.760$ \\
\hline Lymph node metastasis & 0.845 & 1.114 & $0.380-3.267$ & 0.949 & 0.934 & $0.116-7.535$ \\
\hline Resection margin (R0) & 0.177 & 0.545 & $0.225-1.317$ & 0.123 & 0.376 & $0.109-1.301$ \\
\hline KRAS mutations in preoperative serum $\left(\right.$ pre $\left.^{+}\right)$ & 0.710 & 1.182 & $0.489-2.858$ & 0.258 & 0.306 & $0.039-2.381$ \\
\hline KRAS mutations in postoperative serum $\left(\right.$ post $^{+}$) & 0.052 & 2.200 & $0.993-4.873$ & 0.060 & 3.184 & $0.951-10.656$ \\
\hline \multicolumn{7}{|c|}{ Changes in preoperative and postoperative sera } \\
\hline Group 1 (pre $^{-} /$post $^{-}$) & 0.138 & 0.538 & $0.237-1.221$ & 0.263 & 0.497 & $0.146-1.691$ \\
\hline Group 2 (pre $^{-} /$post $^{+}$) & 0.166 & 1.808 & $0.783-4.177$ & 0.025 & 4.155 & $1.197-14.425$ \\
\hline Group 3 (pre $^{+} /$post $\left.^{-}\right)$ & 0.533 & 0.631 & $0.148-2.686$ & 0.417 & 0.039 & $0.000-96.852$ \\
\hline Group $4\left(\right.$ pre $^{+} /$post $^{+}$) & 0.267 & 1.772 & $0.645-4.871$ & 0.751 & 0.712 & $0.087-5.792$ \\
\hline
\end{tabular}

Abbreviations: $\mathrm{Cl}=$ confidence interval; $\mathrm{NACRT}=$ neo-adjuvant chemoradiotherapy.

Table 4B. Multivariate analysis of clinicopathological variables in relation to disease-free and overall survival

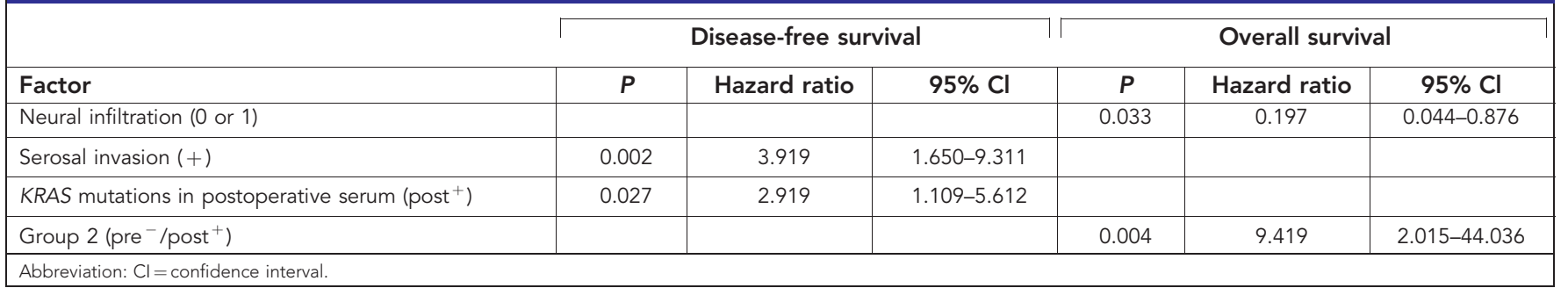

analysis is straightforward and practically relevant in clinical situations.

\section{CONFLICT OF INTEREST}

The authors declare no conflict of interest.

\section{REFERENCES}

Aiura K, Takahashi S, Matsui J, Ueda M, Kitagawa Y (2010) Beneficial effects of 5-fluorouracil and heparin-based portal infusion chemotherapy combined with mitomycin $\mathrm{C}$ and cisplatin after curative resection of pancreatic cancer. Pancreatology 10: 250-258.
Allard WJ, Matera J, Miller MC, Repollet M, Connely MC, Rao C, Tibbe AG, Uhr JW, Terstappne LW (2004) Tumor cells circulate in the peripheral blood of all major carcinomas but not in healthy subjects or patients with nonmalignant diseases. Clin Cancer Res 10: 6897-6904.

Araki T, Shimizu K, Nakamura K, Nakamura T, Mitani Y, Obayashi K, Fujita Y, Kakegawa S, Miyamae Y, Kaira K, Ishidao T, Lezhava A, Hayashizaki Y, Takeyoshi I, Yayamoto K (2010) Usefulness of peptide nucleic acid (PNA)-clamp smart amplification process version 2 (SmartAmp2) for clinical diagnosis of KRAS codon 12 mutations in lung adenocarcinoma: comparison of PNA-clamp SmartAmp2 and PCRrelated methods. J Mol Diagn 12: 118-124.

Cabel L, Proudhon C, Mariani P, Tzanis D, Beinse G, Bieche I, Pierga J Y, Bidard F C (2017) Circulating tumor cells and circulating tumor DNA: what surgical oncologists need to know? Eur J Surg Oncol 43: 949-962.

Diehl F, Schmidt K, Choti MA, Romans K, Goodman S, Li M, Thornton K, Agrawal N, Sokoll L, Szabo SA, KinzlerI KW, Vogelstein B, Diaz Jr LA 
(2008) Circulating mutant DNA to assess tumor dynamics. Nat Med 14: 985-990.

Earl J, Garcia-Nieto S, Martinez-Avila JC, Montans J, Sanjuanbentio A, Rodriguez-Garrote M, Lisa E, Mendia E, Lobo E, Malats N, Carrato A, Guillen-Ponce C (2015) Circulating tumor cells (CTC) and kras mutant circulating free DNA (cfDNA) detection in peripheral blood as biomarkers in patients diagnosed with exocrine pancreatic cancer. BMC Cancer 15: 797.

Fujii-Nishimura Y, NishiyamaI R, Kitago M, Masugi Y, Ueno A, Aiura K, Kawachi S, Kawaida M, Abe Y, Shinoda M, Itano O, Tanimoto A, Sakamoto M, Kitagawa Y (2015) Two cases of pathological complete response to neoadjuvant chemoradiation therapy in pancreatic cancer. Keio J Med 64: 26-31.

Gall TM, Jacob J, Frampton AE, Krell J, Kyriakides C, Castellano L, Stebbing J, Jiao LR (2014) Reduced dissemination of circulating tumor cells with notouch isolation surgical technique in patients with pancreatic cancer. JAMA Surg 149: 482-485.

Gao Y, Zhu Y, Yuan Z (2016) Circulating tumor cells and circulating tumor DNA provide new insights into pancreatic cancer. Int J Med Sci 13: 902-913.

Han JY, Choi JJ, Kim JY, Han YL, Lee GK (2016) PNA clamping-assisted fluorescence melting curve analysis for detecting EGFR and KRAS mutations in the circulating tumor DNA of patients with advanced nonsmall cell lung cancer. BMC Cancer 16: 627.

Hirota M, Shimada S, Yamamoto K, Tanaka E, Sugita H, Egami H, Ogawa M (2005) Pancreatectomy using the no-touch isolation technique followed by extensive intraoperative peritoneal lavage to prevent cancer cell dissemination: a pilot study. JOP 6: 143-151.

Hirota M, Kanemitsu K, Takamori H, Chikamoto A, Tanaka H, Sugita H, Sand J, Nordback I, Baba H (2010) Pancreatoduodenectomy using a notouch isolation technique. Am J Surg 199: e65-e68.

Japan Pancreas Society (2009) Classification of Pancreatic Carcinoma, 2nd English Edn. Kanehara: Tokyo, Japan.

Kim J, Reber HA, Dry SM, Elashoff D, Chen SL, Umetani N, Kitago M, Hines OJ, Kazanjian KK, Hiramatsu S, Bilchik AJ, Yong S, Shoup M, Hoon DS (2006) Unfavourable prognosis associated with K-ras gene mutation in pancreatic cancer surgical margins. Gut 55: 1598-1605.

Kitago M, Ueda K, Aiura K, Suzuki S, Hoshimoto S, Takahashi M, Mukai M, Kitajima M (2004) Comparison of K-ras point mutation distributions in intraductal papillary-mucinous tumors and ductal adenocarcinoma of the pancreas. Int J Cancer 110: 177-182.

Kitago M, Koyanagi K, Nakamura T, Goto Y, Faries M, O'day SJ, Morton DL, Ferrone S, Hoon DS (2009) mRNA expression and BRAF mutation in circulating melanoma cells isolated from peripheral blood with high molecular weight melanoma-associated antigen-specific monoclonal antibody beads. Clin Chem 55: 757-764.

Li T, Zheng Y, Sun H, Zhuang R, Liu J, Liu T, Cai W (2016) K-Ras mutation detection in liquid biopsy and tumor tissue as prognostic biomarker in patients with pancreatic cancer: a systematic review with meta-analysis. Med Oncol 33: 61.

Lo YM, Zhang J, Leung TN, Lau TK, Chang AM, Hjelm NM (1999) Rapid clearance of fetal DNA from maternal plasma. Am J Hum Genet 64: $218-224$.

Mori T, O'day SJ, Umetani N, Martinez SR, Kiago M, Koyanagi K, Kuo C, Takeshima TL, Milford R, Wang HJ, Vu VD, Nguyen SL, Hoon DS (2005) Predictive utility of circulating methylated DNA in serum of melanoma patients receiving biochemotherapy. J Clin Oncol 23: 9351-93518.

Schwarzenbach H, Hoon DS, Pantel K (2011) Cell-free nucleic acids as biomarkers in cancer patients. Nat Rev Cancer 11: 426-437.

Shinozaki M, O'day SJ, Kitago M, Amersi F, Kuo C, Kim J, Wang HJ, Hoon DS (2007) Utility of circulating B-RAF DNA mutation in serum for monitoring melanoma patients receiving biochemotherapy. Clin Cancer Res 13: 2068-2074.

Siegel RL, Miller KD, Jemal A (2016) Cancer statistics, 2016. CA Cancer J Clin 66: 7-30.

Taback B, Bilchik AJ, Saha S, Nakayama T, Wiese DA, Turner RR, Kuo CT, Hoon DS (2004) Peptide nucleic acid clamp PCR: a novel K-ras mutation detection assay for colorectal cancer micrometastases in lymph nodes. Int $J$ Cancer 111: 409-414.

Takahashi S, Aiura K, Saitoh J, Hayatsu S, Kitajima M, Ogata Y (1999) Treatment strategy for pancreatic head cancer: pylorus-preserving pancreatoduodenectomy, Intraoperative radiotherapy and portal catheterization. Digestion 60: 130-134.

Takai E, Totoki Y, Nakamura H, Morizane C, Nara S, Hama N, Suzuki M, Furukawa E, Kato M, Hayashi H, Kohno T, Ueno H, Shimada K, Okusaka T, Nakagawa H, Shibata T, Yachida S (2015) Clinical utility of circulating tumor DNA for molecular assessment in pancreatic cancer. Sci Rep 5: 18425.

This work is published under the standard license to publish agreement. After 12 months the work will become freely available and the license terms will switch to a Creative Commons AttributionNonCommercial-Share Alike 4.0 Unported License. 